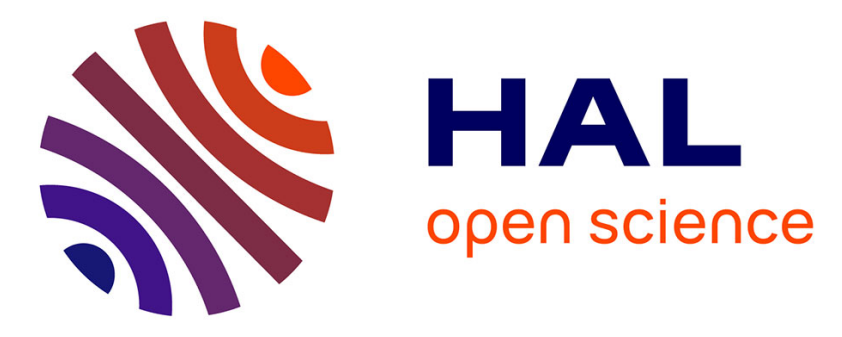

\title{
Modelling surface currents in the Eastern Levantine Mediterranean using surface drifters and satellite altimetry
}

Leila Issa, Julien Brajard, Milad Fakhri, Daniel Hayes, Laurent Mortier, Pierre-Marie Poulain

\section{To cite this version:}

Leila Issa, Julien Brajard, Milad Fakhri, Daniel Hayes, Laurent Mortier, et al.. Modelling surface currents in the Eastern Levantine Mediterranean using surface drifters and satellite altimetry. Ocean Modelling, 2016, 104, pp.1-14. 10.1016/j.ocemod.2016.05.006 . hal-01357669

\section{HAL Id: hal-01357669 \\ https://hal.inria.fr/hal-01357669}

Submitted on 30 Aug 2016

HAL is a multi-disciplinary open access archive for the deposit and dissemination of scientific research documents, whether they are published or not. The documents may come from teaching and research institutions in France or abroad, or from public or private research centers.
L'archive ouverte pluridisciplinaire HAL, est destinée au dépôt et à la diffusion de documents scientifiques de niveau recherche, publiés ou non, émanant des établissements d'enseignement et de recherche français ou étrangers, des laboratoires publics ou privés. 


\title{
Modelling Surface Currents in the Eastern Levantine Mediterranean Using Surface Drifters and Satellite Altimetry
}

\author{
Leila Issa $^{\mathrm{a}, *}$, Julien Brajard ${ }^{\mathrm{b}, \mathrm{c}}$, Milad Fakhri ${ }^{\mathrm{d}}$, Daniel Hayes ${ }^{\mathrm{e}}$, Laurent \\ Mortier $^{\mathrm{b}}$, Pierre-Marie Poulain. ${ }^{\mathrm{f}}$ \\ ${ }^{a}$ Department of Computer Science and Mathematics, Lebanese American University \\ Beirut, Lebanon \\ ${ }^{b}$ Sorbonne Universits UPMC Univ Paris 06 CNRS-IRD-MNHN, LOCEAN Laboratory \\ 4 place Jussieu,75005 Paris, France \\ ${ }^{c}$ Inria Paris-Rocquencourt, Domaine de Voluceau, 78150, Le Chesnay, France \\ ${ }^{d}$ National Centre for Marine Sciences-CNRSL P.O.Box 189, Jounieh, Lebanon \\ ${ }^{e}$ Oceanography Centre University of Cyprus P.O. Box 20537 1678, Nicosia Cyprus \\ ${ }^{f}$ Istituto Nazionale di Oceanografia e di Geofisica Sperimentale (OGS) Borgo Grotta \\ Gigante, 42/c 34010 Sgonico (Trieste), Italy
}

\begin{abstract}
We present a new and fast method for blending altimetry and surface drifters data in the Eastern Levantine Mediterranean. The method is based on a variational assimilation approach for which the velocity is corrected by matching real drifters positions with those predicted by a simple advection model, while taking into account the wind effect. The velocity correction is done in a time-continuous fashion by assimilating at once a whole trajectory of drifters using a sliding time window. Except for the wind component, the velocity is constrained to be divergence free. We show that with few drifters, our method improves the the estimation of velocity in two typical situations: an eddy between the Lebanese coast and Cyprus, and velocities along the Lebanese coast.
\end{abstract}

Keywords: Altimetry, Lagrangian data, data assimilation, drifters, surface velocity field, Eastern Levantine Mediterranean

\footnotetext{
*Corresponding author Tel: +9611786456, ext 1298, Email: leila.issa@lau.edu.lb
} 


\section{Introduction}

An accurate estimation of mesoscale to sub-mesoscale surface dynamics of the ocean is critical in several applications in the Eastern Levantine Mediter-

ranean basin. For instance, this estimation can be used in the study of pollutant dispersion emanating from heavily populated coastal areas. Small scale and accurate surface velocity estimation near coastal areas could also benefit the study of the paths of alien Lessepsian species. A good knowledge of the surface velocity field is thus important but can be challenging, especially when direct observations are relatively sparse.

Altimetry has been widely used to predict the mesoscale features of the global ocean resolving typically lengths on the order of $100 \mathrm{~km}$ (Chelton et al., 2007). There are, however, limitations to its usage. It is inaccurate in resolving short temporal and spatial scales of some physical structures like eddies, fronts and filaments, which results in blurring these structures. Further errors and inaccuracies occur near the coastal areas (within 20-50 $\mathrm{km}$ from land), where satellite information is degraded; this is due to various factors such as land contamination, inaccurate tidal and geophysical corrections, inaccurate Mean Dynamic Topography and incorrect removal of high frequency atmospheric effects at the sea surface (Caballero et al., 2014).

To improve geostrophic velocities, especially near the coast, in situ observations provided by surface drifters can be considered (e.g. Bouffard et al. (2008); Ruiz et al. (2009)). Drifters follow the currents and when numerous, they allow for an extensive spatial coverage of the region of interest. They are inexpensive, easily deployable and provide accurate information on their position and other environmental parameters (Lumpkin and Pazos, 2007).

To illustrate the information provided by drifters data, we show in Figure 1 the real-time positions of three drifters launched south of Beirut on August 28 2013. These positions can be compared to the positions that would have been obtained if the drifters were advected by the altimetric velocity field. We observe that unlike the corresponding positions simulated by the altimetric field provided by AVISO (see section 2.1), the drifters stay within 10-20 km from the coast. The background velocity field shown in the figure is the geostrophic field predicted by altimetry and averaged over a period of 6 days. The drifters' in situ data render a more precise image of the local surface velocity than the altimetric one; however, this only possible along the path following their trajectory. These types of data are therefore complementary. 
Numerous studies aim at exploiting the information provided by drifters (Lagrangian data) to improve the Eulerian surface velocity. A large number of these rely on modifying a dynamical model of this velocity by minimizing the distance between observed and model simulated drifters trajectories. This variational assimilation approach, which was classically used in weather predictions (Courtier et al., 1994; Le Dimet and Talagrand, 1986), was tested successfully in this context, by using several types of models for the velocity, such as idealized point vortex models (Kuznetsov et al., 2003), General Circulation Models with simplified stratification (e.g. Kamachi and O'Brien (1995); Molcard et al. (2005); Özgökmen et al. (2003), Nodet (2006)). However, in applications involving pollutant spreading such as the ones we are interested in, a fast diagnosis of the velocity field is needed in areas where a priori knowledge of this field is not available. This prompts the need for model that is simple, fast, and easy to implement, while keeping the essential physical features of the velocity field. In this work, we propose a new algorithm that blends geostrophic and drifters data in an optimal way. The method is based on a simple advection model for the drifters, that takes into account the wind effect and that imposes a divergence free constraint on the geostrophic component. The algorithm is used to estimate the surface velocity field in the Eastern Levantine basin, in particular in the region between Cyprus and the Syrio-Lebanese coast, a part of the Mediterranean basin that has not been so well studied in the literature before.

From the methodological point of view, combining altimetric and drifters data has been done using statistical approaches, with availability of extensive data sets. A common approach is to use regression models to combine geostrophic, wind and drifters components, with the drifters' velocity component being computed from drifters' positions using a pseudo-Lagrangian approach. When large data sets are available, this approach produces an unbiased refinement of the geostrophic circulation maps, with better spatial resolution. (e.g. Poulain et al. (2012); Menna et al. (2012); Uchida and Imawaki (2003); Maximenko et al. (2009); Niiler et al. (2003); Stanichny et al. (2015)). Another approach relies on variational assimilation: the work of Taillandier et al. (2006a) is based on a simple advection model for the drifters' positions that is matched to observations via optimization. The implementation of this method first assumes the time-independent approximation of the velocity correction, then superimposes inertial oscillations on the mesoscale field. These variational techniques had led to the development of the so called "LAgrangian Variational Analysis" (LAVA) algorithm. LAVA 
was initially tested and applied to correct model velocity fields using drifter trajectories (Taillandier et al., 2006b, 2008) and later customized to several other applications such as model assimilation (Chang et al., 2011; Taillandier et al., 2010) and more recently to blending drifters and altimetry to estimate surface currents in the Gulf of Mexico (Berta et al., 2015).

From the application point of view, blending drifters and altimetric data has been successfully applied to several basins, for example in: the Gulf of Mexico (Berta et al., 2015), the Black Sea (Kubryakov and Stanichny, 2011; Stanichny et al., 2015) the North Pacific (Uchida and Imawaki, 2003), and the Mediterranean Sea (Taillandier et al., 2006b; Poulain et al., 2012; Menna et al., 2012). In Menna et al. (2012), there was a particular attention to the levantine sub-basin, where large historical data sets from 1992 to 2010 were used to characterize the surface currents. The specific region which lies between the coasts of Lebanon, Syria and Cyprus is however characterized by a scarcity of data. In the present work, we use in addition to the data sets used in Menna et al. (2012), more recent data from 2013 (in the context of the AltiFloat project) to study this particular region.

Our contribution focuses on the methodological aspect, and it can be considered an extension of the variational approach used in Taillandier et al. (2006a). The purpose is to add physical considerations to the surface velocity estimation, without making the method too complex, in order to still allow for Near Real Time applications. We provide a time-continuous correction by: (i) assimilating a whole trajectory of drifters at once, (ii) using a moving time window where observations are correlated, (iii) constraining the velocity correction to be divergence-free, and (iv) adding a component to the velocity due to the effect of the wind, in the fashion done in Poulain et al. (2009).

We show that with a few drifters, the proposed method improves the estimation of an eddy between the Lebanese coast and Cyprus, and predicts real drifters trajectories along the Lebanese coast.

This manuscript is organized as follows. We begin in section 2 by describing the data sets used in the method and the validation process. In section 3 , we provide a thorough description of the method including definition of the parameters, the linearized advection and the optimization procedure. We validate the method by conducting sensitivity analyses in section 4 , followed by two real experiments in section 5 , one in a coastal area and another in an offshore eddy. 


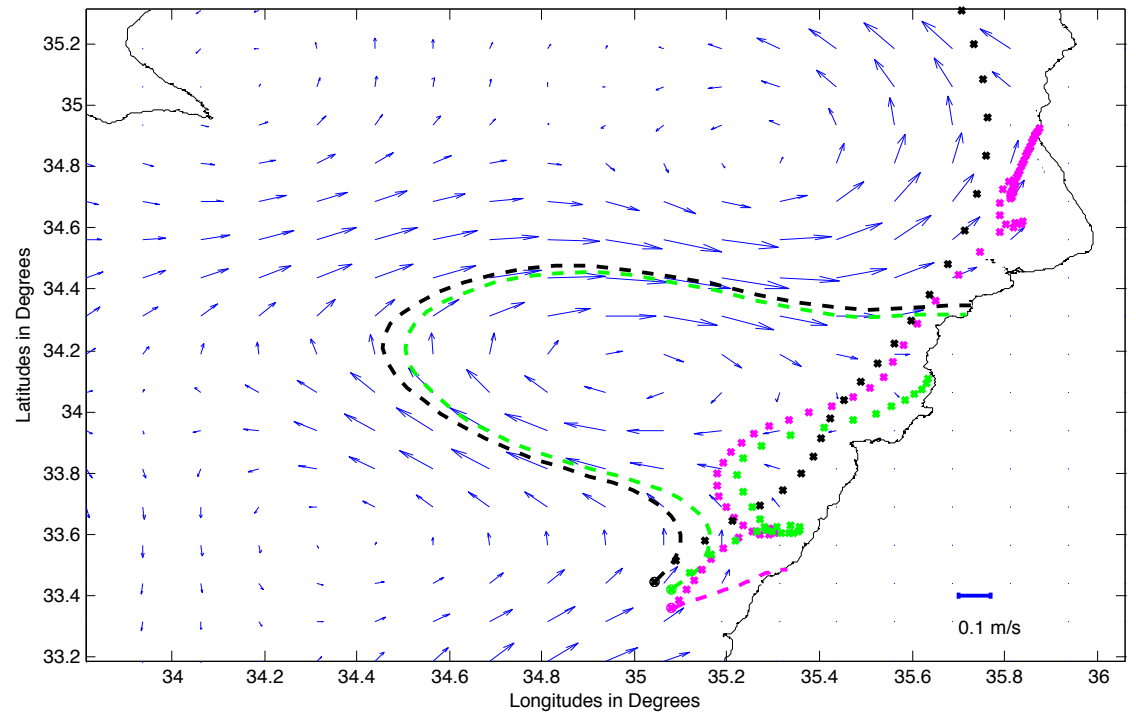

Figure 1: AltiFloat drifters deployed on 28 Aug. 2013 (shown in $-\mathrm{x}$ ) versus trajectories simulated using the AVISO field (shown in --). The velocity field shown is the AVISO field, averaged over 6 days from 28 Aug. 2013 to 3 Sept. 2013 


\section{Data}

All the data detailed in this section were extracted from two target periods: on one hand the data associated with the NEMED project ${ }^{1}$ from 25 August 2009 to 3 September 2009, and on the other hand the data associated with the AltiFloat project from 28 August 2013 to 4 September 2013.

\subsection{Altimetry data}

Geostrophic surface velocity fields used as a background in the study were produced by Ssalt/Duacs and distributed by AVISO ${ }^{2}$. Altimetric mission used were Saral, Cryosat-2, Jason-1\&2. The geostrophic absolute velocity fields were deduced from Maps of Absolute Dynamic Topography (MADT) of the regional Mediterranean Sea product using the recently released Mean Dynamic Topography by Rio et al. (2014).

Data were mapped daily at a resolution of $1 / 8^{\circ}$. Data were linearly interpolated every hour at the advection model time step.

\subsection{Drifters data}

Drifters were deployed during two target periods, 2 drifters were selected for the first period in 2009 and 3 in the second period in 2013. Table 1 presents a summary of the 5 drifters used in this study. Drifter models were SVP designs with a drogue at a nominal depth of $15 \mathrm{~m}$. Drifter positions were edited, interpolated and filtered with a low-pass filter in order to remove high-frequency current component especially inertial currents. The final time series were obtained by sampling every $6 \mathrm{~h}$. A more complete description of the drifters and the data processing procedure can be found in Poulain et al. (2009).

\subsection{Wind Data}

ECMW ERA-Interim 6-hourly wind products (Dee et al., 2011) were extracted in order to estimate the effect of the wind and wind-driven currents on the drifters. Wind velocities closest to the surface $(10 \mathrm{~m})$ were extracted at a resolution of $1 / 8^{\circ}$ at the same grid point as the AVISO data. The data were resampled on a hourly time step.

\footnotetext{
${ }^{1}$ http://nettuno.ogs.trieste.it/sire/drifter/nemed/nemed_main.html

${ }^{2}$ ww. aviso.altimetry.fr
} 


\begin{tabular}{|c|c|c|c|c|c|c|}
\hline Project & Deploy Date & Lat & Lon & Last Date & Lat & Lon \\
\hline NEMED & 29 Jul. 2009 & 31.90 & 34.42 & 28 Oct. 2009 & 34.1 & 31.77 \\
\hline NEMED & 03 Aug. 2009 & 32.59 & 32.63 & 26 Dec. 2009 & 32.92 & 34.28 \\
\hline AltiFloat & 27 Aug. 2013 & 33.28 & 34.95 & 22 Sep. 2013 & 36.77 & 35.94 \\
\hline AltiFloat & 27 Aug. 2013 & 33.28 & 34.98 & 04 Sep. 2013 & 34.13 & 35.64 \\
\hline AltiFloat & 27. Aug. 2013 & 33.28 & 35.03 & 17 Sep. 2013 & 34.88 & 35.88 \\
\hline
\end{tabular}

Table 1: List of drifters used to illustrate the methodology presented in this study, 2 drifters deployed in 2009 (results are detailed in section 5.2) and 3 drifter were deployed in 2013 (results are detailed in sections 5.1)

Wind velocities were used to estimate the wind-driven effect on drifters' velocity. The Eulerian velocity field in the advection model (Eq. 3) is the sum of the geostrophic velocity and the wind induced velocity (Eq. 8) given by the formula (Poulain et al., 2009) (for SVP drifter with drogue attached):

$$
\mathbf{U}_{\text {wind }}=0.007 \exp \left(-27^{\circ} i\right) \times \mathbf{U}_{\mathbf{1 0}}
$$

where $\mathbf{U}_{\text {wind }}=u_{\text {wind }}+i v_{\text {wind }}$ is the drifter's velocity induced by the overall effect of the wind and $\mathbf{U}_{\mathbf{1 0}}=u_{10}+i v_{10}$ is the wind velocity above the surface $(10 \mathrm{~m})$ expressed as complex numbers.

\subsection{Model data}

Modeled surface velocity fields for September 2013 were used to calibrate the assimilation method presented in section 3. The model selected was the CYCOFOS-CYCOM high resolution model (Zodiatis et al., 2003, 2008) that covers the Northeast Levantine basin $(1 \mathrm{~km}$ resolution, west and south boundaries extended to $31^{\circ} 00^{\prime} \mathrm{E}$ and $33^{\circ} 00^{\prime} \mathrm{N}$ and north and east reach land). The model forecasts were used without assimilation and were re-interpolated on a $1 / 8^{\circ}$ grid point with a time step of one hour.

\section{Method}

\subsection{Statement of the problem}

We consider $N_{f}$ Lagrangian drifters released at time $t=0$ at various locations. These drifters provide their positions every $\Delta t$, over a period 
$\left[0, T_{f}\right]$. Our objective is to determine an estimate of the two-dimensional Eulerian surface velocity field

$$
\mathbf{u}(x, y, t)=(u(x, y, t), v(x, y, t))
$$

characterized by a typical length scale $R$, given observations of the drifters' positions

$$
\mathbf{r}_{i}^{o b s}(n \Delta t), \quad i=1,2, \cdots, N_{f}, \quad n=1,2, \cdots N, \text { where } N \Delta t=T_{f} .
$$

The velocity shall be estimated on a specified grid with resolution of $1 / 8^{\circ}$ in both longitude and latitude, and in the time frame $\left[0, T_{f}\right]$.

The estimation is done following a variational assimilation approach (Courtier et al., 1994; Le Dimet and Talagrand, 1986), whereby the background $\mathbf{u}_{\mathbf{b}}$, is corrected by matching the observed drifter positions with those predicted by a simple model presented in subsection 3.2. This correction is obtained using a sliding time window of size $T_{w}$, where we assume $\Delta t<T_{w} \leq T_{L}$, and where $T_{L}$ is the Lagrangian time scale associated with the drifters in the concerned region. The background field is considered to be the sum of a geostrophic component (provided by altimetry) on which we impose a divergence free constraint, and a velocity component due to the wind. The details of this procedure are given in subsection 3.3.

\subsection{Linearized model for Lagrangian data}

The position of a specific drifter $\mathbf{r}(t)=(x(t), y(t))$ is the solution of the non-linear advection equation

$$
\frac{d \mathbf{r}}{d t}=\mathbf{u}(\mathbf{r}(t), t), \quad \mathbf{r}(0)=\mathbf{r}_{0}, \mathbf{u}(x, y, 0)=\mathbf{u}_{0} .
$$

This equation is integrated numerically, for example, using an Euler scheme. Since the drifters positions do not coincide with the Eulerian velocity's grid points, a spatial interpolation of $\mathbf{u}$ to these positions is needed.

The observation operator, denoted schematically by $\mathbf{r}=\mathcal{M}(\mathbf{u}, \mathbf{r})$, consists then of numerical advection and interpolation $\mathcal{I}$, and it is given by

$$
\mathbf{r}(k \delta t)=\mathbf{r}((k-1) \delta t)+\delta t \mathcal{I}(\mathbf{u}((k-1) \delta t), \mathbf{r}((k-1) \delta t)), \quad k=1,2, \cdots
$$


where $\delta t$ the time step of the scheme, typically a fraction of $\Delta t$. We choose bilinear interpolation

$$
\begin{aligned}
\mathcal{I}(\mathbf{u},(x, y)) & =\mathbf{u}_{1}+\left(\mathbf{u}_{2}-\mathbf{u}_{1}\right) \frac{\left(x-x_{1}\right)}{\Delta x}+\left(\mathbf{u}_{3}-\mathbf{u}_{1}\right) \frac{\left(y-y_{1}\right)}{\Delta y} \\
& +\left(\mathbf{u}_{1}-\mathbf{u}_{2}-\mathbf{u}_{3}+\mathbf{u}_{4}\right) \frac{\left(x-x_{1}\right)\left(y-y_{1}\right)}{\Delta x \Delta y}
\end{aligned}
$$

where

$$
\begin{aligned}
& \mathbf{u}_{1}=\mathbf{u}\left(x_{1}, y_{1}\right), \\
& \mathbf{u}_{2}=\mathbf{u}\left(x_{1}+\Delta x, y_{1}\right), \\
& \mathbf{u}_{3}=\mathbf{u}\left(x_{1}, y_{1}+\Delta y\right), \\
& \mathbf{u}_{4}=\mathbf{u}\left(x_{1}+\Delta x, y_{1}+\Delta y\right) .
\end{aligned}
$$

Here, $\left(x_{1}, y_{1}\right)$ is the position of the southwest corner of the grid cell containing $(x, y)$.

Using the incremental approach (Courtier et al., 1994), the nonlinear observation operator $\mathcal{M}$ is linearized around a reference state. In a specific time window, we consider time independent perturbations $\delta \mathbf{u}$ on top of the background velocity field, that is

$$
\begin{aligned}
\mathbf{r} & =\mathbf{r}^{\mathbf{b}}+\delta \mathbf{r} \\
\mathbf{u} & =\mathbf{u}^{\mathbf{b}}+\delta \mathbf{u}
\end{aligned}
$$

The linearized equations become

$$
\begin{aligned}
& \mathbf{r}^{\mathbf{b}}(k \delta t)=\mathbf{r}^{\mathbf{b}}((k-1) \delta t)+\delta t \mathcal{I}\left(\mathbf{u}^{\mathbf{b}}((k-1) \delta t)\right), \mathbf{r}^{\mathbf{b}}((k-1) \delta t), \quad \text { background } \\
& \delta \mathbf{r}(k \delta t)=\delta \mathbf{r}((k-1) \delta t)+\delta t\left\{\mathcal{I}\left(\delta \mathbf{u}, \mathbf{r}^{\mathbf{b}}((k-1) \delta t)\right)\right. \\
& \left.+\delta \mathbf{r}((k-1) \delta t) \cdot \partial_{(x, y)} \mathcal{I}\left(\mathbf{u}^{\mathbf{b}}((k-1) \delta t), \mathbf{r}^{\mathbf{b}}((k-1) \delta t)\right)\right\}, \text { tangent }
\end{aligned}
$$

where the drifters' positions are initialized with observations, and where $k=$ $1,2,3, \cdots\left\lfloor T_{w} / \delta t\right\rfloor$. Here, $\partial_{(x, y)} \mathcal{I}$ is the derivative of the interpolation operator with respect to $(x, y)$.

The background velocity used in the advection of the drifters is the superposition of a geostrophic component $\mathbf{u}_{\text {geo }}$ provided by altimetry and a 
component driven by the wind $\mathbf{u}_{\text {wind }}$, which is parametrized by two parameters as described in section 2 (Poulain et al., 2009). So we have

$$
\mathbf{u}^{b}=\mathbf{u}_{g e o}+\mathbf{u}_{\text {wind }}
$$

The wind component is added to bring the corrected velocity field closer to reality. The effect of the wind and the corresponding contribution to the total velocity depend on the weather conditions. In the experiments presented in this work, we found out that the effect of the wind on the overall velocity is negligible (1\% to $2 \%$ percent of the total velocity).

\subsection{Algorithm for velocity correction}

The algorithm proposed performs a sequence of optimizations over a moving time window of size $T_{w}$. For each time window, the correction $\delta \mathbf{u}$ is obtained by minimizing the following objective function

$$
\begin{aligned}
\mathcal{J}(\delta \mathbf{u}) & =\sum_{i=1}^{N_{f}} \sum_{m=1}^{\left\lfloor T_{w} / \Delta t\right\rfloor}\left\|\mathbf{r}_{i}^{b}\left(\mathbf{u}^{\mathbf{b}}\right)+\delta \mathbf{r}_{i}(\delta \mathbf{u})-\mathbf{r}_{i}^{o b s}(m \Delta t)\right\|^{2} \\
& +\alpha_{1}\|\delta \mathbf{u}\|_{\mathbf{B}}^{2}+\alpha_{2} \sum_{i, j}(\nabla \cdot \delta \mathbf{u})^{2} .
\end{aligned}
$$

Note that while $\delta \mathbf{u}$ is time independent for a specific time window, it varies as the window moves. This series of optimizations yield a time varying correction to the velocity field.

The first component of the objective function (Eq. 9) quantifies the misfit between the model obtained by iterations of Eq. 7, and observations $\mathbf{r}^{o b s}(m \Delta t)$. We highlight the dependence of $\mathbf{r}^{b}$ on the background velocity only, whereas $\delta \mathbf{r}$ depends on both background and correction. The second component requires the corrected field to stay close to the background velocity. Here the $B$-norm is defined as $\|\psi\|_{\mathbf{B}}^{2} \equiv \psi^{T} \mathbf{B}^{-1} \psi$, where $\mathbf{B}$ is the error covariance matrix. This term serves the dual purpose of regularization and information spreading or smoothing. To obtain $\mathbf{B}$, we use the diffusion filter method of Weaver and Courtier (2001), where a priori information on the typical length scale $R$ of the Eulerian velocity is employed. The parameter $\alpha_{1}$ represents the relative weight of this regularization term with respect to the other terms. The last component is a constraint on the geostrophic part of the velocity, required to stay divergence free. This term is added to ensure a physical correction, avoiding artifacts especially near the coasts. It 
promotes the emergence of eddies and forces the field to go along the coast not perpendicular to it.

Inside a specific time window, trajectories of all the drifters over the duration $T_{w}$, contribute to give a constant correction in time $\delta \mathbf{u}$. In order to produce a smooth time-dependent velocity field in $\left[0, T_{f}\right]$, a sliding window, of time shift $\sigma$, is used to obtain correction $\delta \mathbf{u}_{k}$ in

$$
\left[k \sigma, k \sigma+T_{w}\right], k=0,1,2 \cdots .
$$

The reconstructed velocity is then obtained as a superposition of the time dependent background field and the weighted corrections

$$
\mathbf{u}_{\text {corrected }}\left(t_{i}\right)=\mathbf{u}^{\mathbf{b}}\left(t_{i}\right)+\sum_{k=0}^{N_{w}^{i}-1} w_{k} \delta \mathbf{u}_{k}
$$

A correction at a specific instant $t_{i}$ takes into account only $N_{w}^{i}$ windows sliding through $t_{i}$. The weight is inversely proportional to the "distance" between time $t_{i}$ and the window's position according to

$$
w_{k}=\frac{1}{\left|k-k^{*}\right|+1}
$$

where $k^{*}$ corresponds to the window centered at $t_{i}$. Note here that the weights are normalized to add to one.

We end this section by pointing out that we implement the algorithm described above in YAO (Badran et al., 2008), a numerical tool that is well adapted to variational assimilation problems which simplifies the computation and implementation of the adjoint needed in the optimization. Minimization was carried out using the M1QN3 minimizer (Gilbert and Lemaréchal, 1989), linked to YAO. The convergence of the assimilation in a typical time window $T_{w}=24 \mathrm{~h}$ takes 20 seconds on a sequential code compiled on a CPU Intel(R) Core(TM) running at $3.40 \mathrm{GHz}$.

\section{Sensitivity analyses}

To validate our method, we conducted a set of synthetic experiments where the observations were simulated using a known or "true" velocity field, 
denoted by $\mathbf{u}_{\text {true }}$, and provided by the CYCOFOS-CYCOM model (see subsection 2.4). This allows us to assess the validity of our approach by comparing the corrected, $\mathbf{u}_{\text {corrected }}$, and true fields, based on the time-dependent RMS error

$$
\operatorname{error}(u, t)=\left(\frac{\sum_{i, j}\left\|\mathbf{u}_{\text {true }}(i, j, t)-\mathbf{u}(i, j, t)\right\|^{2}}{\sum_{i, j}\left\|\mathbf{u}_{\text {true }}(i, j, t)\right\|^{2}}\right)^{1 / 2} .
$$

Here, $\|$.$\| refers the the L_{2}$ norm of a vector, and $\mathbf{u}$ could be the background velocity, $\mathbf{u}_{b}$, giving the error before assimilation or the corrected velocity, $\mathbf{u}_{\text {corrected }}$, giving the error after assimilation. The background velocity used is given by Eq. 8, where the geostrophic component is provided by AVISO. Note that the CYCOFOS-CYCOM model was initialized by a large scale model having assimilated AVISO data.

The configuration of our experiment was the following: we put ourselves in the same context as that of the real drifter experiment conducted during the AltiFloat project, by the CNRS-L, the Lebanese national research council (refer to AltiFloat drifters in Table 1), where the drifters were launched south of Beirut starting the end of August 2013. As shown in Fig. 2, we deployed "synthetic" drifters in the region located between $33.7^{\circ}$ and $34.25^{\circ}$ North and $34.9^{\circ} \mathrm{E}$ and the coast. The initial positions of the two drifters shown in red coincide with the positions of two AltiFloat drifters on 1 September 2013 (by that time, the third AltiFloat drifter had left the region of interest). The drifters' positions were simulated using a velocity field $\mathbf{u}_{\text {true }}$ obtained from the CYCOM model. The experiment lasted for a duration of $T_{f}=3$ days. In principle, nothing forbids us of conducting longer experiments, but in this coastal region, the drifters had hit land after 3 days, as shown in Fig. 2, likely because of easterly winds.

Using the relative RMS error before and after assimilation as a measure, we studied the sensitivity of our method to the window size $T_{w}$, the time shift of the sliding window $\sigma$, the number of drifters $N_{f}$ and to the sampling time $\Delta t$. We also assessed the effect of the divergence free constraint term.

A sensitivity analysis yielded the optimal choice of $R=20 \mathrm{~km}$ used in the diffusion filter, which is consistent with the range of values found in the Northwestern Mediterranean (Taillandier et al., 2006a).

\subsection{Sensitivity to the time window size}

We first show the effect of the window size, $T_{w}$. This parameter has to be within the Lagrangian time scale $T_{L}$, estimated here to be $1-3$ days, 


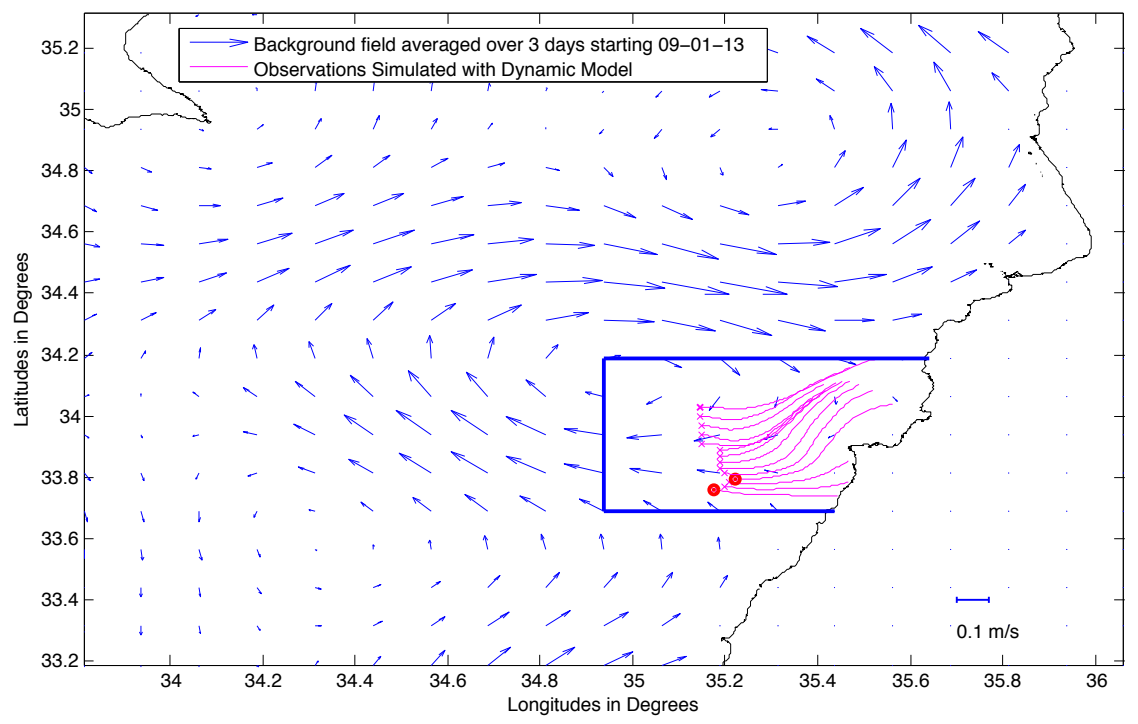

Figure 2: Region of RMS error computation for the sensitivity experiments. Observations generated by CYCOM model starting on 1 Sept. 2013 (for 3 days) are shown on top of the background field. The red locations correspond to AltiFloat drifters' locations. 
but it cannot be too large because we consider corrections that are time independent in each window. In Fig. 3, we show the results corresponding to various window sizes (fixing $N_{f}=14$ and $\Delta t=2 \mathrm{~h}$ ), by displaying the relative RMS error, computed in the box shown in Fig. 2, before and after the correction. Note that for all the window sizes considered, the time shift of the sliding windows was selected to yield minimal error. We first see that the error curves (after correction) in Fig. 3 tend to increase generally as time increases. This behavior may be attributed to the fact that, for this special coastal configuration, the first three drifters hit the shore after $48 \mathrm{~h}$, and also due to the interaction of the spatial filter with land. We also observe that the optimal window size for this configuration is $24 \mathrm{~h}$, which is within the range mentioned above. The error in this case is almost half of the error before correction. We mention here that for this coastal scenario, window sizes of three days or more caused the algorithm to become ill conditioned, which is expected due to the fact that the correction is fixed in a specific window, as mentioned before.

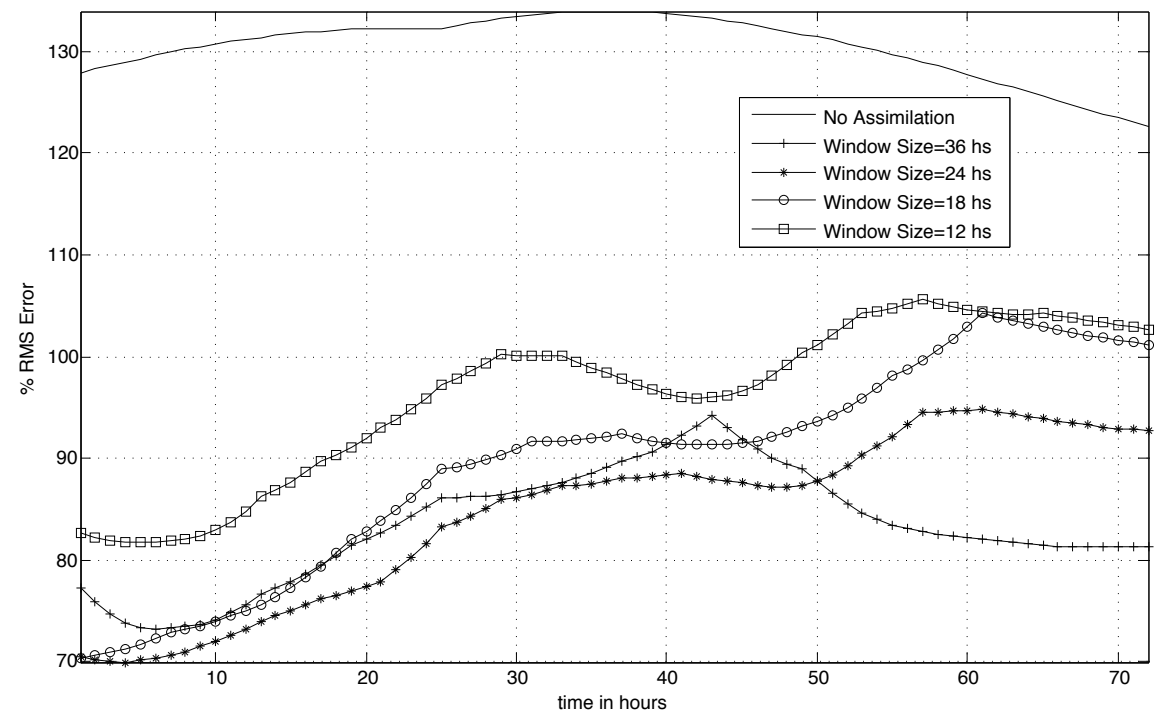

Figure 3: The effect of the window size. Error before correction is shown with a solid line. Errors after are shown with symbols for several window sizes. $N_{f}=14$ and $\Delta t=2 \mathrm{~h}$ 


\subsection{Sensitivity to the time shift of the sliding window}

We present here the effect of varying, $\sigma$, the time shift of the sliding window. The values considered were $\sigma=0,6,8$ and $12 \mathrm{~h}$. Note that $\sigma=0$ amounts to doing separate corrections. The window size, sampling time, and number of drifters were fixed to $T_{w}=24 \mathrm{~h}, \Delta t=2 \mathrm{~h}$, and $N_{f}=14$ respectively. In Fig. 4, we show the results by displaying the relative RMS error before and after the correction. We observe here that if the corrections are done separately, the correction is not smooth; in fact smaller values of $\sigma$ yield not only smoother, but better corrections, especially close to the middle of the experiment's duration. This may be explained by the fact that the moving window is responsible for spreading the information smoothly in the domain. The improvement is also likely due to the weights that favor corrections by the nearest set of drifters at the given time. This is not the case when the windows are separate, for example the error in the velocity correction at the edge of the windows is larger, because the nearest adjacent window does not contribute to this correction.

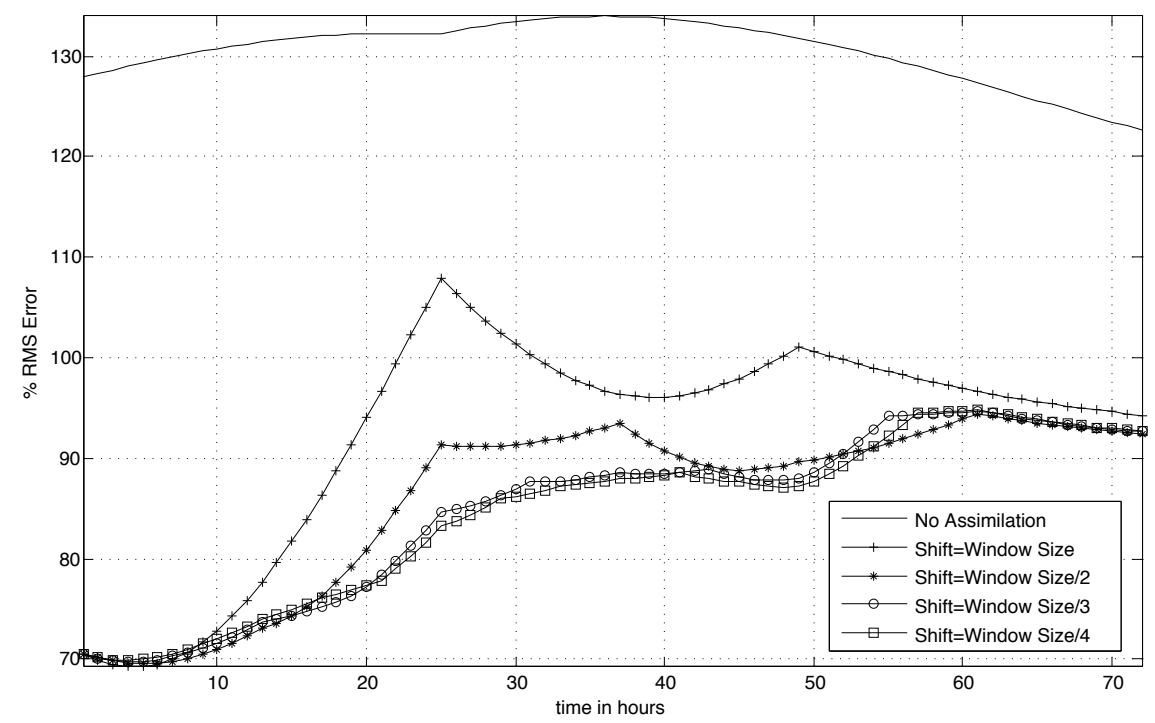

Figure 4: The effect of the moving window: smaller shifts $\sigma$ yield smoother and better corrections. $N_{f}=14, \Delta t=2 \mathrm{~h}, T_{w}=24 \mathrm{~h}$. 


\subsection{Sensitivity to the number of drifters}

The effect of the number of drifters, $N_{f}$, is shown next in Fig. 5. Respecting coverage, we started with $N_{f}=14$ (positioned as shown in Fig. 2), then reduced it to 10,6, and 3. Naturally more drifters yielded a better correction but we notice that even with three drifters, the error was still reduced by $20 \%$ and much more so close to the beginning of the experiment. We also show in this figure the effect of removing the drifters that fail before the end of the experiment: the corresponding error is shown in the dashed curve of Fig. 5, and it is evenly distributed in time as expected.

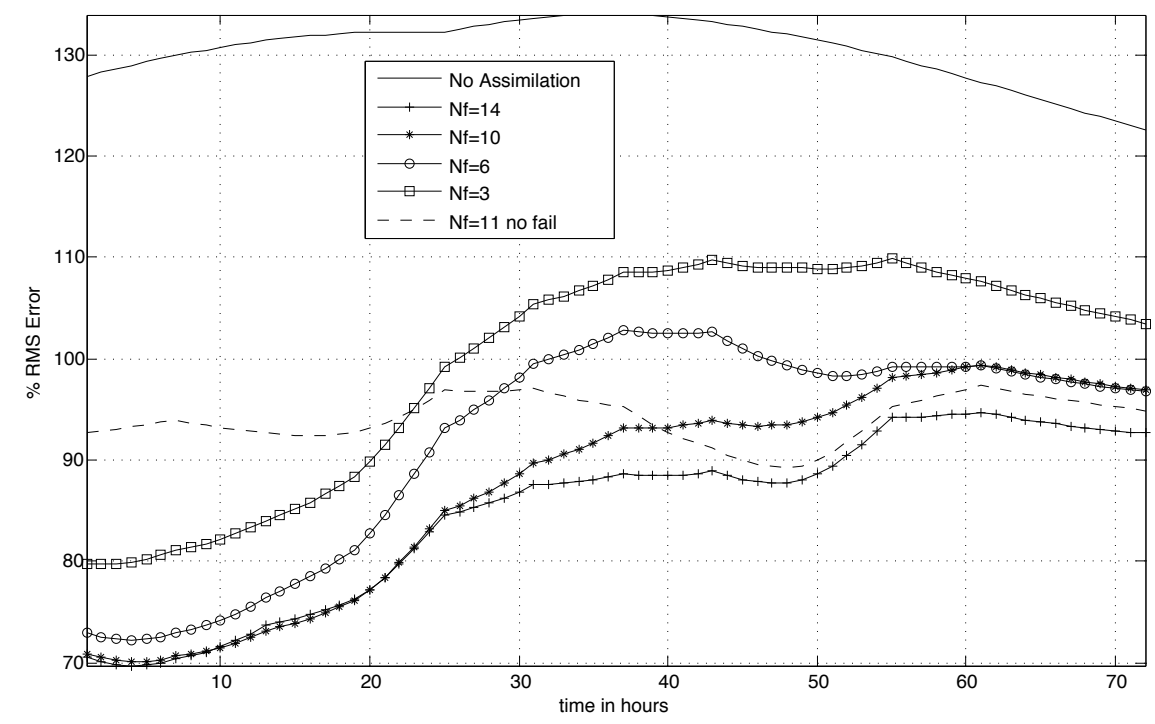

Figure 5: The effect of the number of drifters. More drifters yield better corrections but corrections are possible with 3 drifters only. The dashed line shows the effect of just taking drifters that do not hit the shore before the end of the experiment. Here $T_{w}=24 \mathrm{~h}$ and $\Delta t=2 \mathrm{~h}$.

\subsection{Sensitivity to the sampling time}

We show the effect of the sampling time $\Delta t$ of the observations in Fig. 6 . Curves after correction correspond to $\Delta t=6,4$ and 2 hours and as we see from the figure, the difference between these cases is not too large. The realistic scenario of $\Delta t=6 \mathrm{~h}$ still yielded a very good correction. 


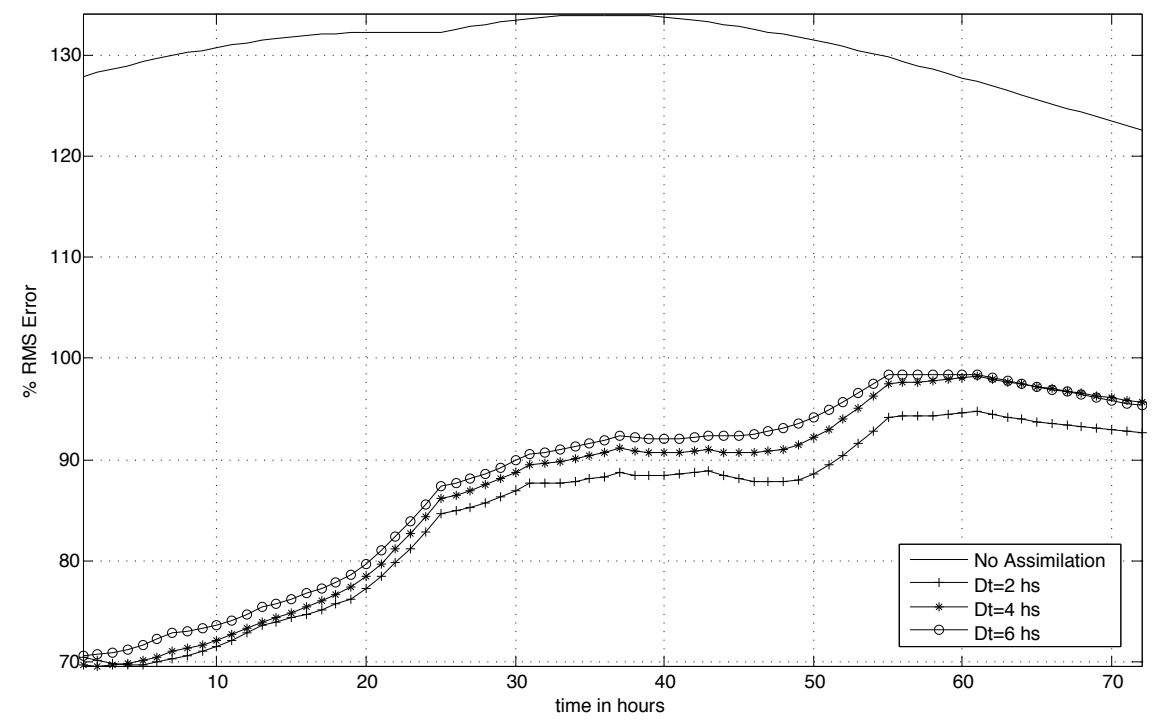

Figure 6: The effect of the sampling time $\Delta t$ of the observations. Here $T_{w}=24 \mathrm{~h}$, and $N_{f}=14$. The realistic scenario of $\Delta t=6 \mathrm{~h}$ is not too far from the smallest $\Delta t=2 \mathrm{~h}$.

\subsection{Sensitivity to the effect of the divergence constraint}

The role of the divergence constraint in the optimization is determined by a delicate balance between the various terms. This term should be non negligible because as mentioned earlier, it forces the correction to be in the direction tangent to the coast, making the component perpendicular to the coast small. However, it cannot be too strong as to interfere with the regularization term, because that would make the optimization ill-conditioned. To show its effect on the correction, we conducted a sensitivity experiment where we compared the results (in the same setting as the previous experiments) with and without this term. As seen from Fig. 7, we obtained an improvement of about $10 \%$ in the overall error if this term was present in the cost function. This is expected because we are correcting the velocity in a region close to the coast.

\subsection{Summary of results}

For the experiment with the optimal choice of parameters $\left(T_{w}=24 \mathrm{~h}\right.$, $\sigma=6 \mathrm{~h}, N_{f}=14$ and $\Delta t=2$ ), we compared the trajectories of the drifters 


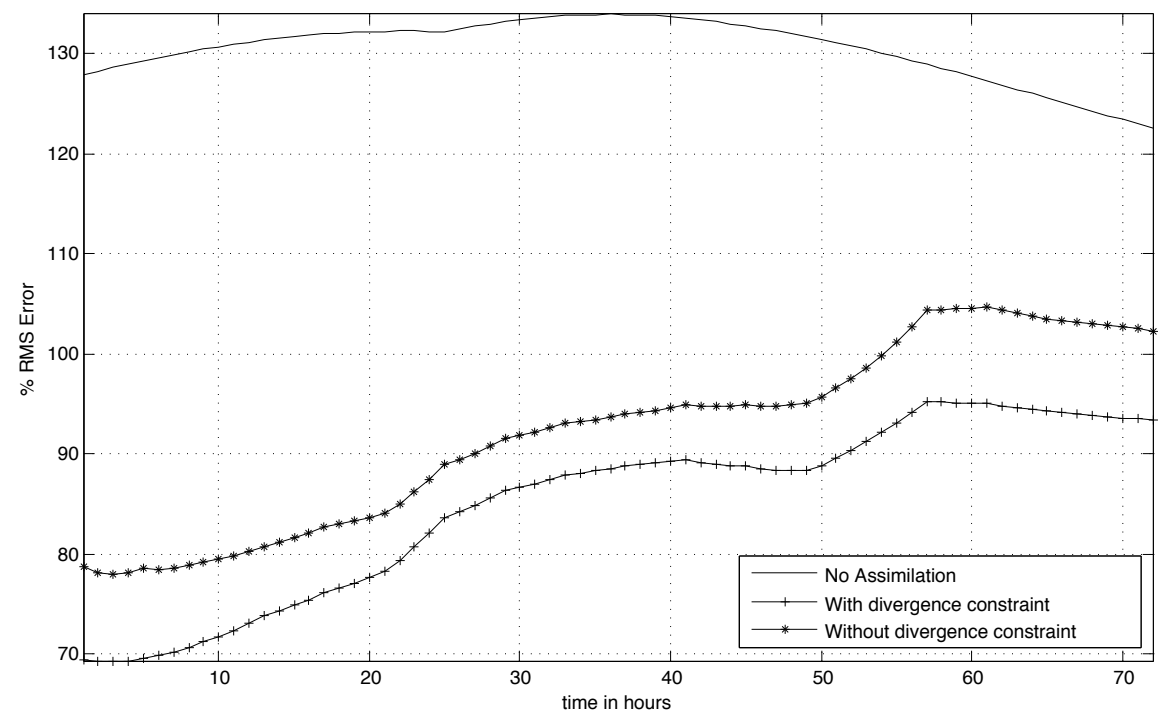

Figure 7: The effect of divergence constraint. The curve in $-*-$ is obtained without the divergence constraint $\left(\alpha_{2}=0\right.$ in Eq. 9) whereas the one in -+is obtained by adding the divergence constraint. An improvement of about $10 \%$ in the error is observed in this coastal setting. Here $T_{w}=24 \mathrm{~h}, \Delta t=6$ h, $\sigma=6 \mathrm{~h}$, and $N_{f}=14$. 
simulated with the corrected velocity field with the "true" observations. We also compared background and corrected fields in the region of interest. In Fig. 8, we display the point-wise $L_{2}$ error between the true field and either the background or corrected fields. This error is defined as the time average of

$$
\operatorname{error}(u, i, j, t)=\left\|\mathbf{u}_{\text {true }}(i, j, t)-\mathbf{u}(i, j, t)\right\| .
$$

The left panel corresponds to the "before" picture, where the error is between the background and true fields and the right one corresponds to the "after" picture, where the error is between the corrected and true fields. On top of that, we observe the excellent agreement between the positions of the drifters simulated with the corrected field and the true observations. Next, the correction in terms of the velocity direction is shown in Fig. 9: we display the cosine of the angle between the background and true field on the left side versus the cosine of the angle between the corrected and true fields on the right. Note that a cosine of one indicates a strong correlation (dark red) in direction between the two fields. We see this strong correlation between true and corrected fields by observing how the blue color (left pannel of Fig.9) turns into deep red (right pannel of Fig.9) in the region where the drifters were deployed. Finally, in Fig. 10, we show the actual current maps before and after correction. We clearly see that the drifters corrected the poorly

represented coastal meander in the AVISO altimetric velocity field.

\section{Experiments with Real Data}

The methodology described in section 3 was applied to two case studies: one along the Lebanese coast and one in an eddy southeast of Cyprus.

\subsection{Improvement of velocity field near the coast}

Three drifters were launched on 28 August 2013 from the South of Beirut, at the positions shown in circles in Fig. 11. They provide their position every $\Delta t=6 \mathrm{~h}$ and stay within $20 \mathrm{~km}$ of the coast for the duration of the experiment. The experiment considered here lasts for six days (a time frame where the three drifters are still spatially close before two of them hit the shore). The window size and the time shift of the sliding window were chosen to be $T_{w}=24 \mathrm{~h}$ and $\sigma=6 \mathrm{~h}$ respectively.

Fig. 11 shows that the trajectories simulated with the corrected field and the observed ones are in very good agreement, even for small scale structures 

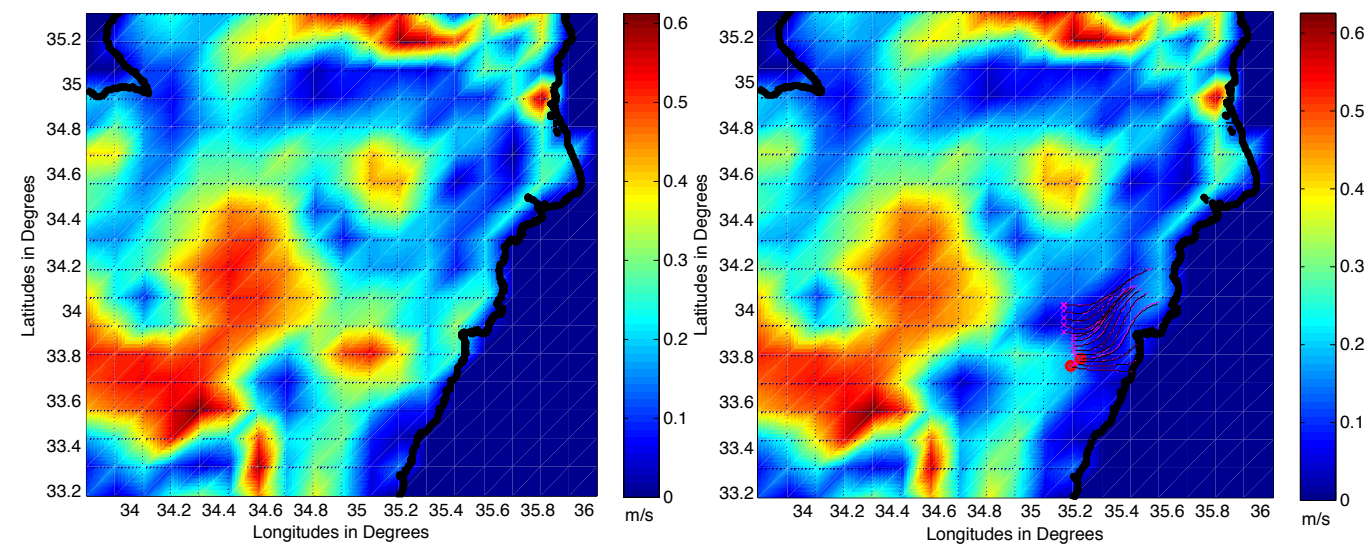

Figure 8: Point-wise $L_{2}$ error averaged over time, before (left) and after (right) correction. In the right frame, drifters' positions obtained by simulation with corrected field (magenta) versus "true" observations(black) are shown on top of the error.
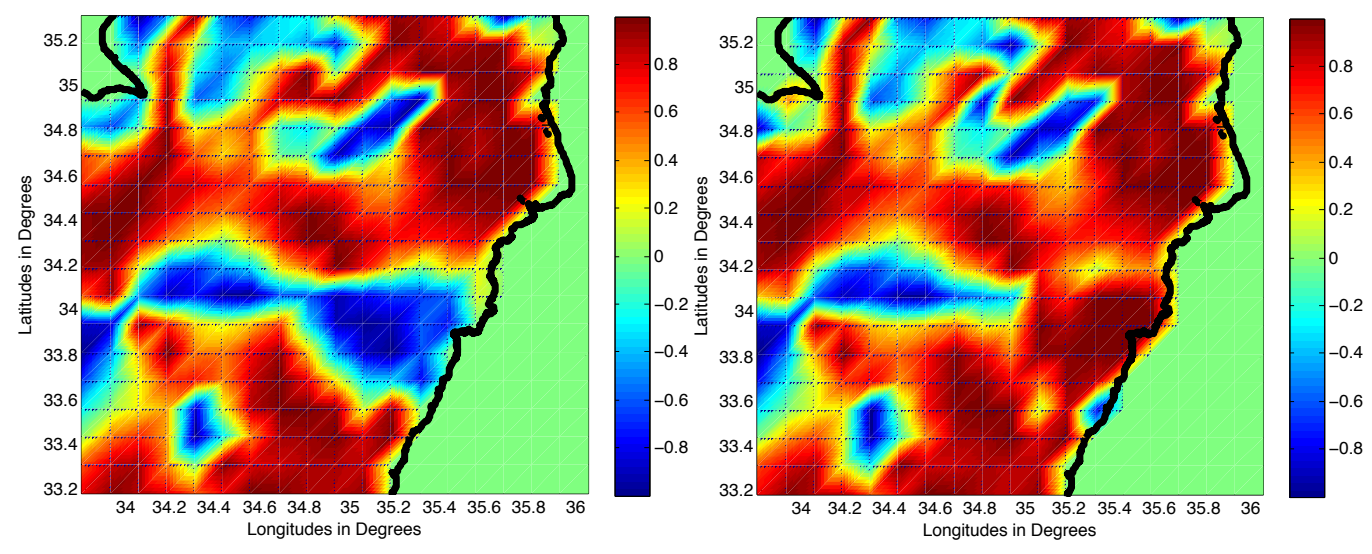

Figure 9: Correction in terms of direction. Left: $\cos \left(\mathbf{u}_{b}, \mathbf{u}_{\text {true }}\right)$, right: $\cos \left(\mathbf{u}_{\text {corrected }}, \mathbf{u}_{\text {true }}\right)$. 


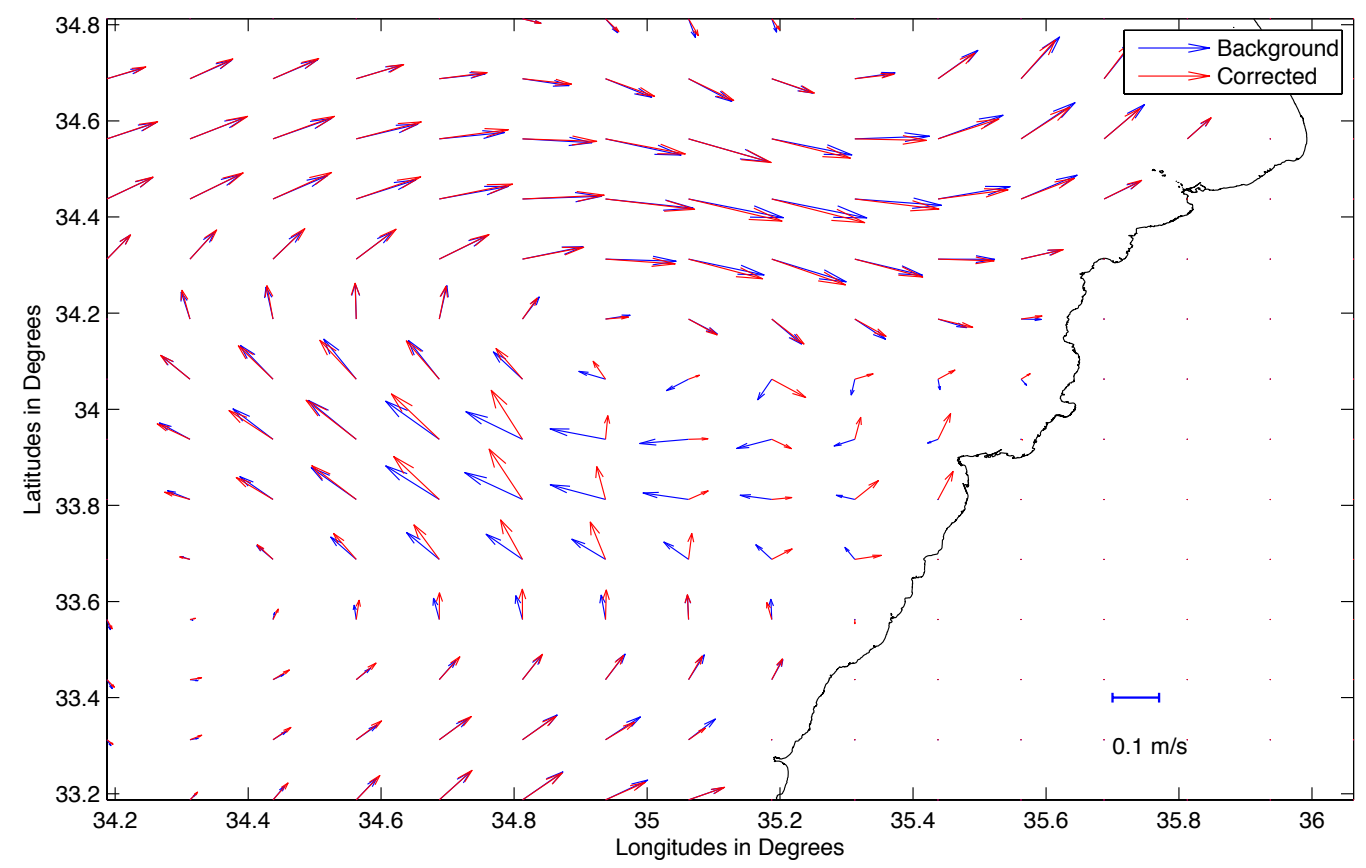

Figure 10: Background velocity field (blue) versus corrected velocity field (red) for the sensitivity experiment with the optimal choice of parameters. 
near the coast. Note that the correction presented in the figure is the time average of the instantaneous corrections, over a period of 6 days. As expected, the velocity field is modified in the neighborhood of the drifters trajectories. It can be noticed that the main effect of the correction is to increase the velocity parallel to the coast, and decrease the velocity normal to the coast. The background field was determined using altimetric data and is expected to have significant bias close to the coast (Bouffard et al., 2008), and the consequence is that the method is able to correct some of this bias.

To validate more quantitatively the corrected velocities, a sensitivity study was carried out. Only two drifters (the eastern-most magenta drifter and the western-most black drifter) were assimilated in order to correct the velocity field. The third drifter is used only to validate the corrected field by comparing its actual trajectory with the simulated trajectory using the velocity field. Figure 12 shows the results of this experiment. The real drifter trajectory (empty circle with thin line) is compared to the simulated trajectory using either the background field (bold cyan line) or the corrected field (bold green line). It can be noticed that the trajectory is greatly improved using the corrected field. It shows that the corrected field can be used to simulate realistic trajectories in the neighborhood of the assimilation positions, even in a coastal region. This can be a decisive point for applications such as pollutant transport estimation.

\subsection{Improvement of velocity field in an eddy}

In the context of the NEMED deployment (see section 2.2), we selected 2 drifters trajectories from 25 August 2009 to 3 September 2009. The AVISO velocity field was corrected by assimilating successive positions of the drifters every six hours. In this experiment the window size $T_{w}$ was chosen to be 72 $\mathrm{h}$ as the velocity field was more stable in this case than in coastal areas. The shifting of the time window was chosen to be $\sigma=18 \mathrm{~h}$.

In Fig. 13, the trajectory of the drifters are represented in gray, the mean AVISO surface geostrophic velocity field in blue and the mean corrected geostrophic field in red. It can be observed that the real trajectory of the drifters and the simulated trajectory using the total corrected field (sum of corrected field in red and the wind-induced velocity) are indiscernible. The mean position error is $0.96 \mathrm{~km}$ with a maximum of $6.7 \mathrm{~km}$.

In this case, the drifter trajectories are chosen to be situated in an eddy. The AVISO field is produced by an interpolation method which tends to overestimate the spatial extent of the eddy and underestimate its intensity. 


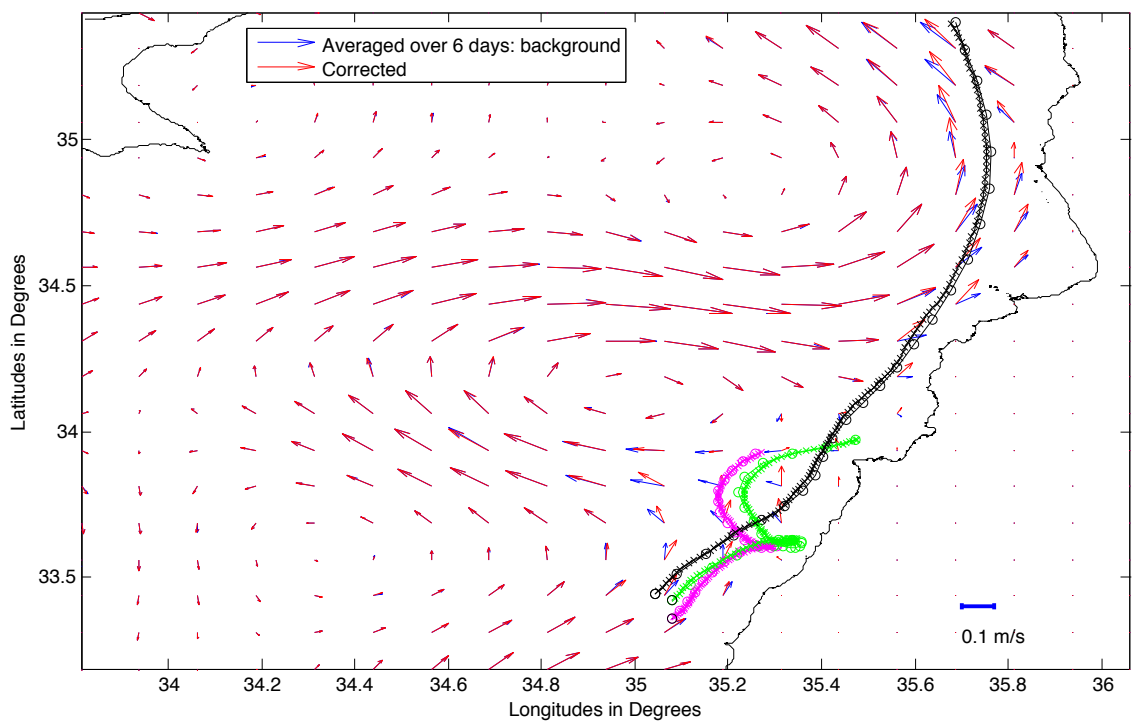

Figure 11: Prediction of the positions of 3 AltiFloat drifters, launched on 28 Aug. 2013. $T_{f}=6$ days. $T_{w}=24 \mathrm{~h}$ and $\sigma=6 \mathrm{~h}$. Positions of drifters simulated with corrected field (cross markers) are shown on top of observed positions (circle markers). Corrected field is shown in red whereas background field is shown in blue.

In order to estimate the effect of the assimilation on the eddy characteristics, we computed the Okubo-Weiss parameter (Isern-Fontanet et al., 2004) on the mean velocity fields before correction (background) and after correction. Eddies are characterized by a negative Okubo-Weiss parameter, the value of the parameter is an indicator of the intensity of the eddy. Colored distributions of the Okubo-Weiss parameter before and after correction are shown in Fig. 14. After correction, the Okubo-Weiss parameter has greater absolute values and a slightly smaller spatial extent (bottom figure) which is an improvement to the AVISO processing bias (top figure). This result constitutes a validation of the assimilation method presented in this paper showing that eddies were better resolved after assimilating drifter trajectories.

\section{Conclusion}

A novel and efficient method for blending altimetry and surface drifters data was presented. The method is based on a variational assimilation ap- 


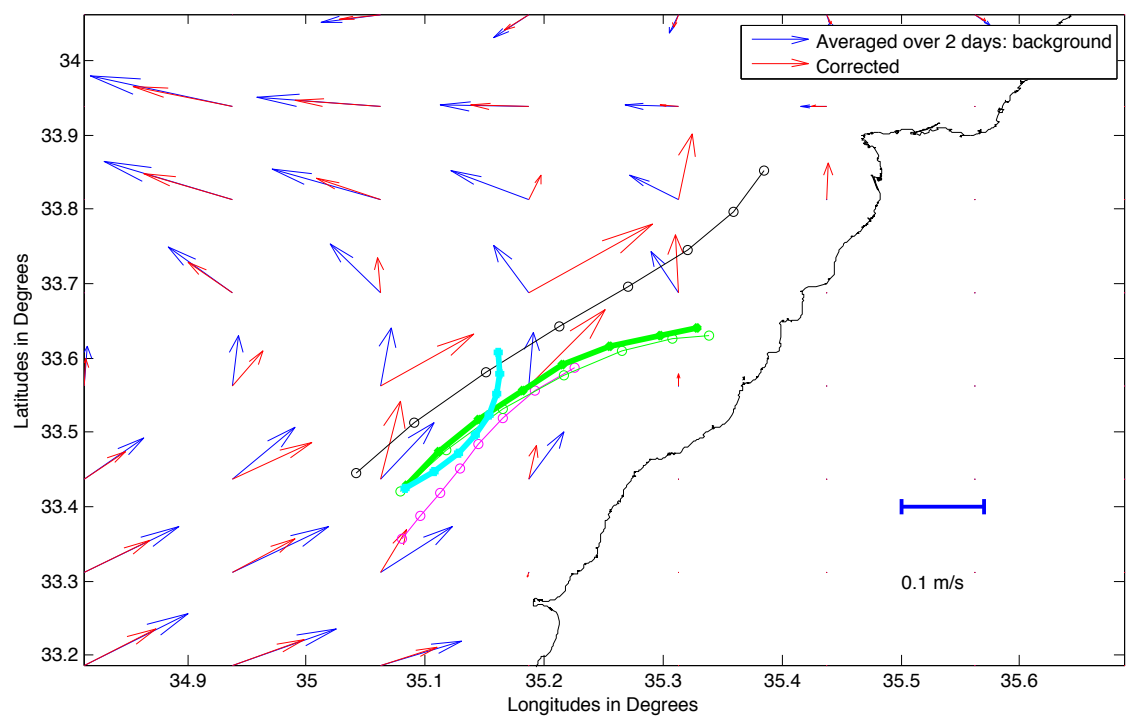

Figure 12: Prediction of the position of the green drifter using the observed black and magenta drifters. $T_{f}=2$ days. $T_{w}=24 \mathrm{~h}$ and $\sigma=6 \mathrm{~h}$. Position of the green drifter simulated with corrected field is shown in green squares, on top of observed position shown in light green circles. Compare to the position of the drifter obtained with background field only, shown in cyan. Corrected field is shown in red whereas background field is shown in blue.

proach for which the velocity is corrected by matching observed drifters positions with those predicted by a simple advection model, taking into account the wind effect and imposing a divergence free condition on the geostrophic part of the velocity. The velocity correction is done in a time-continuous fashion by assimilating at once a whole trajectory of drifters using a sliding time window. Sensitivity analyses showed that significant improvement in the estimation of the velocity field can be achieved for a proper choice of the window size and time shift, even when few drifters are used. We found that assimilating two successive drifter positions produces a correction of the velocity field within a radius of $20 \mathrm{~km}$ and for approximatively $24 \mathrm{~h}$ before and after the measurement. The method was applied to two real experiments, one close to the Lebanese coast and one in a off-shore eddy between Lebanon and Cyprus. In these two scenarios, the method was able to correct some typical weaknesses of altimetric fields, in particular the estimation of velocity 


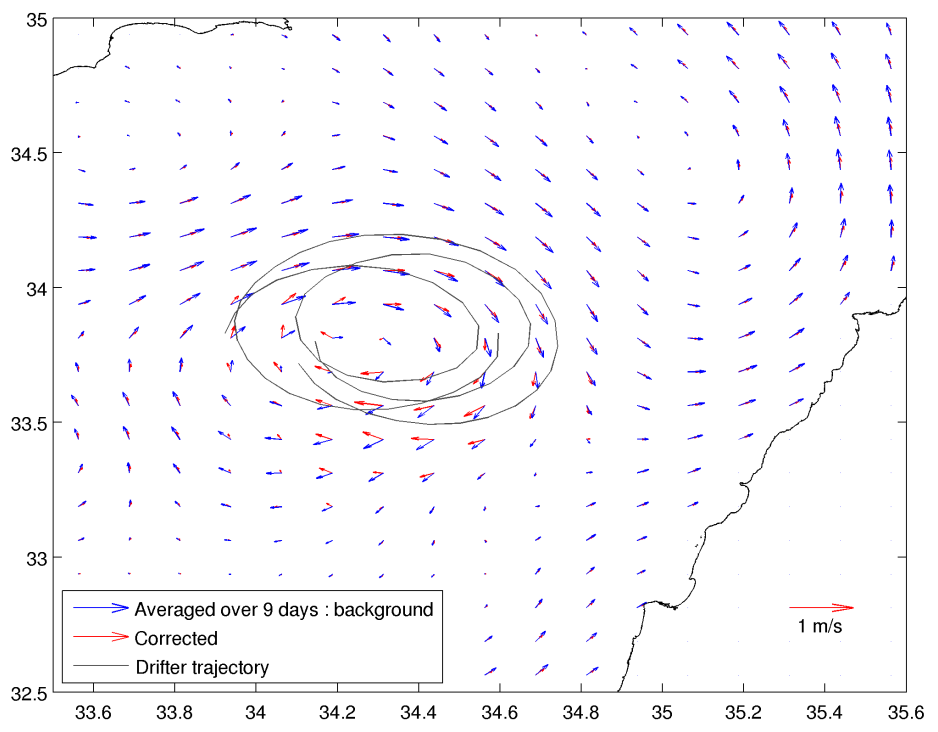

Figure 13: Corrected surface velocity field (in red) compared to AVISO background field (in blue). The assimilated drifter trajectories are represented in gray. The North-West coast in the figure is Cyprus.

near the coast and accurate estimation of eddies dimensions and intensity. The algorithm needed very few computational resources and was quick to converge, rendering it well fitted for near-real time applications.

\section{Acknowledgement}

The altimeter products were produced by Ssalto/Duacs and distributed by AVISO, with support from CNES (http://www.aviso.altimetry.fr/duacs/).

Wind data were produced by ECMWF and downloaded from (http://apps.ecmwf.int/datasets/data/interim-full-daily/).

This work was partially funded by the ENVI-Med program in the framework of the AltiFloat project and by the U.S. Office of Naval Research under grant N00014081094.

The Lebanese CNRS funded the campaign of drifters' deployment using the research vessel "CANA". The AltiFloat MetOcean Iridium drifters (SVP) were provided by the Istituto Nazionale di Oceanografia e di Geofisica 
Sperimentale (OGS), Italy and LOCEAN institute of "Pierre et Marie Curie University", France. The drifter data are distributed by the MedSVP portal of OGS. We thank A. Bussani and M. Menna for processing the drifter data.

\section{Bibliography}

Badran, F., Berrada, M., Brajard, J., Crépon, M., Sorror, C., Thiria, S., Hermand, J.-P., Meyer, M., Perichon, L., Asch, M., 2008. Inversion of satellite ocean colour imagery and geoacoustic characterization of seabed properties: Variational data inversion using a semi-automatic adjoint approach. Journal of marine systems 69 (1), 126-136.

Berta, M., Griffa, A., Magaldi, M. G., Özgökmen, T. M., Poje, A. C., Haza, A. C., Olascoaga, M. J., 2015. Improved surface velocity and trajectory estimates in the gulf of mexico from blended satellite altimetry and drifter data. Journal of Atmospheric and Oceanic Technology (2015).

Bouffard, J., Vignudelli, S., Cipollini, P., Menard, Y., 2008. Exploiting the potential of an improved multimission altimetric data set over the coastal ocean. Geophysical Research Letters 35 (10).

Caballero, I., Gomez-Enri, J., Cipollini, P., Navarro, G., 2014. Validation of high spatial resolution wave data from envisat ra-2 altimeter in the gulf of cádiz. Geoscience and Remote Sensing Letters, IEEE 11 (1), 371-375.

Chang, Y., Hammond, D., Haza, A., Hogan, P., Huntley, H., Kirwan, A., Lipphardt, B., Taillandier, V., Griffa, A., Özgökmen, T., 2011. Enhanced estimation of sonobuoy trajectories by velocity reconstruction with nearsurface drifters. Ocean Modelling 36 (3), 179-197.

Chelton, D. B., Schlax, M. G., Samelson, R. M., de Szoeke, R. A., 2007. Global observations of large oceanic eddies. Geophysical Research Letters $34(15)$.

Courtier, P., Thépaut, J.-N., Hollingsworth, A., 1994. A strategy for operational implementation of 4d-var, using an incremental approach. Quarterly Journal of the Royal Meteorological Society 120 (519), 1367-1387.

Dee, D. P., Uppala, S. M., Simmons, A. J., Berrisford, P., Poli, P., Kobayashi, S., Andrae, U., Balmaseda, M. A., Balsamo, G., Bauer, P., Bechtold, P., 
Beljaars, A. C. M., van de Berg, L., Bidlot, J., Bormann, N., Delsol, C., Dragani, R., Fuentes, M., Geer, A. J., Haimberger, L., Healy, S. B., Hersbach, H., Hólm, E. V., Isaksen, L., Kållberg, P., Köhler, M., Matricardi, M., McNally, A. P., Monge-Sanz, B. M., Morcrette, J.-J., Park, B.-K., Peubey, C., de Rosnay, P., Tavolato, C., Thépaut, J.-N., Vitart, F., 2011. The era-interim reanalysis: configuration and performance of the data assimilation system. Quarterly Journal of the Royal Meteorological Society 137 (656), 553-597.

URL http://dx.doi.org/10.1002/qj.828

Gilbert, J. C., Lemaréchal, C., 1989. Some numerical experiments with variable-storage quasi-newton algorithms. Mathematical programming 45 (1-3), 407-435.

Isern-Fontanet, J., Font, J., García-Ladona, E., Emelianov, M., Millot, C., Taupier-Letage, I., 2004. Spatial structure of anticyclonic eddies in the algerian basin (mediterranean sea) analyzed using the okubo-weiss parameter. Deep Sea Research Part II: Topical Studies in Oceanography 51 (25), 3009-3028.

Kamachi, M., O'Brien, J., 1995. Continuous data assimilation of drifting buoy trajectory into an equatorial pacific ocean model. Journal of Marine Systems 6 (1), 159-178.

Kubryakov, A., Stanichny, S., 2011. Mean dynamic topography of the black sea, computed from altimetry, drifter measurements and hydrology data. Ocean Science 7 (6), 745-753.

Kuznetsov, L., Ide, K., Jones, C., 2003. A method for assimilation of lagrangian data. Monthly Weather Review 131 (10), 2247-2260.

Le Dimet, F.-X., Talagrand, O., 1986. Variational algorithms for analysis and assimilation of meteorological observations: theoretical aspects. Tellus A 38 (2), $97-110$.

Lumpkin, R., Pazos, M., 2007. Measuring surface currents with surface velocity program drifters: the instrument, its data, and some recent results. Lagrangian analysis and prediction of coastal and ocean dynamics, 39-67. 
Maximenko, N., Niiler, P., Centurioni, L., Rio, M.-H., Melnichenko, O., Chambers, D., Zlotnicki, V., Galperin, B., 2009. Mean dynamic topography of the ocean derived from satellite and drifting buoy data using three different techniques*. Journal of Atmospheric and Oceanic Technology 26 (9), 1910-1919.

Menna, M., Poulain, P.-M., Zodiatis, G., Gertman, I., 2012. On the surface circulation of the levantine sub-basin derived from lagrangian drifters and satellite altimetry data. Deep Sea Research Part I: Oceanographic Research Papers 65, 46-58.

Molcard, A., Griffa, A., Özgökmen, T. M., 2005. Lagrangian data assimilation in multilayer primitive equation ocean models. Journal of Atmospheric and Oceanic Technology 22 (1), 70-83.

Niiler, P., Maximenko, N., Panteleev, G., Yamagata, T., Olson, D., 2003. Near-surface dynamical structure of the kuroshio extension. Journal of Geophysical Research: Oceans (1978-2012) 108 (C6).

Nodet, M., 2006. Variational assimilation of lagrangian data in oceanography. Inverse problems 22 (1), 245.

Özgökmen, T. M., Molcard, A., Chin, T. M., Piterbarg, L. I., Griffa, A., 2003. Assimilation of drifter observations in primitive equation models of midlatitude ocean circulation. Journal of Geophysical Research: Oceans (1978-2012) 108 (C7).

Poulain, P.-M., Gerin, R., Mauri, E., Pennel, R., 2009. Wind effects on drogued and undrogued drifters in the eastern mediterranean. Journal of Atmospheric and Oceanic Technology 26 (6), 1144-1156.

Poulain, P.-M., Menna, M., Mauri, E., 2012. Surface geostrophic circulation of the mediterranean sea derived from drifter and satellite altimeter data. Journal of Physical Oceanography 42 (6), 973-990.

Rio, M. H., Pascual, A., Poulain, P.-M., Menna, M., Barceló-Llull, B., Tintoré, J., et al., 2014. Computation of a new mean dynamic topography for the mediterranean sea from model outputs, altimeter measurements and oceanographic in situ data. Ocean Science 10 (4), 731-744. 
Ruiz, S., Pascual, A., Garau, B., Faugère, Y., Alvarez, A., Tintoré, J., 2009. Mesoscale dynamics of the balearic front, integrating glider, ship and satellite data. Journal of Marine Systems 78, S3-S16.

Stanichny, S. V., Kubryakov, A. A., Soloviev, D. M., 2015. Parameterization of surface wind-driven currents in the black sea using drifters, wind, and altimetry data. Ocean Dynamics, 1-10.

Taillandier, V., Dobricic, S., Testor, P., Pinardi, N., Griffa, A., Mortier, L., Gasparini, G., 2010. Integration of argo trajectories in the mediterranean forecasting system and impact on the regional analysis of the western mediterranean circulation. Journal of Geophysical Research: Oceans (1978-2012) 115 (C3).

Taillandier, V., Griffa, A., Molcard, A., 2006a. A variational approach for the reconstruction of regional scale eulerian velocity fields from lagrangian data. Ocean Modelling 13 (1), 1-24.

Taillandier, V., Griffa, A., Poulain, P., Signell, R., Chiggiato, J., Carniel, S., 2008. Variational analysis of drifter positions and model outputs for the reconstruction of surface currents in the central adriatic during fall 2002. Journal of Geophysical Research: Oceans (1978-2012) 113 (C4).

Taillandier, V., Griffa, A., Poulain, P.-M., Béranger, K., 2006b. Assimilation of argo float positions in the north western mediterranean sea and impact on ocean circulation simulations. Geophysical research letters 33 (11).

Uchida, H., Imawaki, S., 2003. Eulerian mean surface velocity field derived by combining drifter and satellite altimeter data. Geophysical research letters $30(5)$.

Weaver, A., Courtier, P., 2001. Correlation modelling on the sphere using a generalized diffusion equation. Quarterly Journal of the Royal Meteorological Society 127 (575), 1815-1846.

Zodiatis, G., Lardner, R., Hayes, D., Georgiou, G., Sofianos, S., Skliris, N., Lascaratos, A., 2008. Operational ocean forecasting in the eastern mediterranean: implementation and evaluation. Ocean Science 4, 31-47.

Zodiatis, G., Lardner, R., Lascaratos, A., Georgiou, G., Korres, G., Syrimis, M., 2003. High resolution nested model for the cyprus, ne levantine basin, 
eastern mediterranean sea: implementation and climatological runs. In: Annales Geophysicae. Vol. 21. pp. 221-236. 

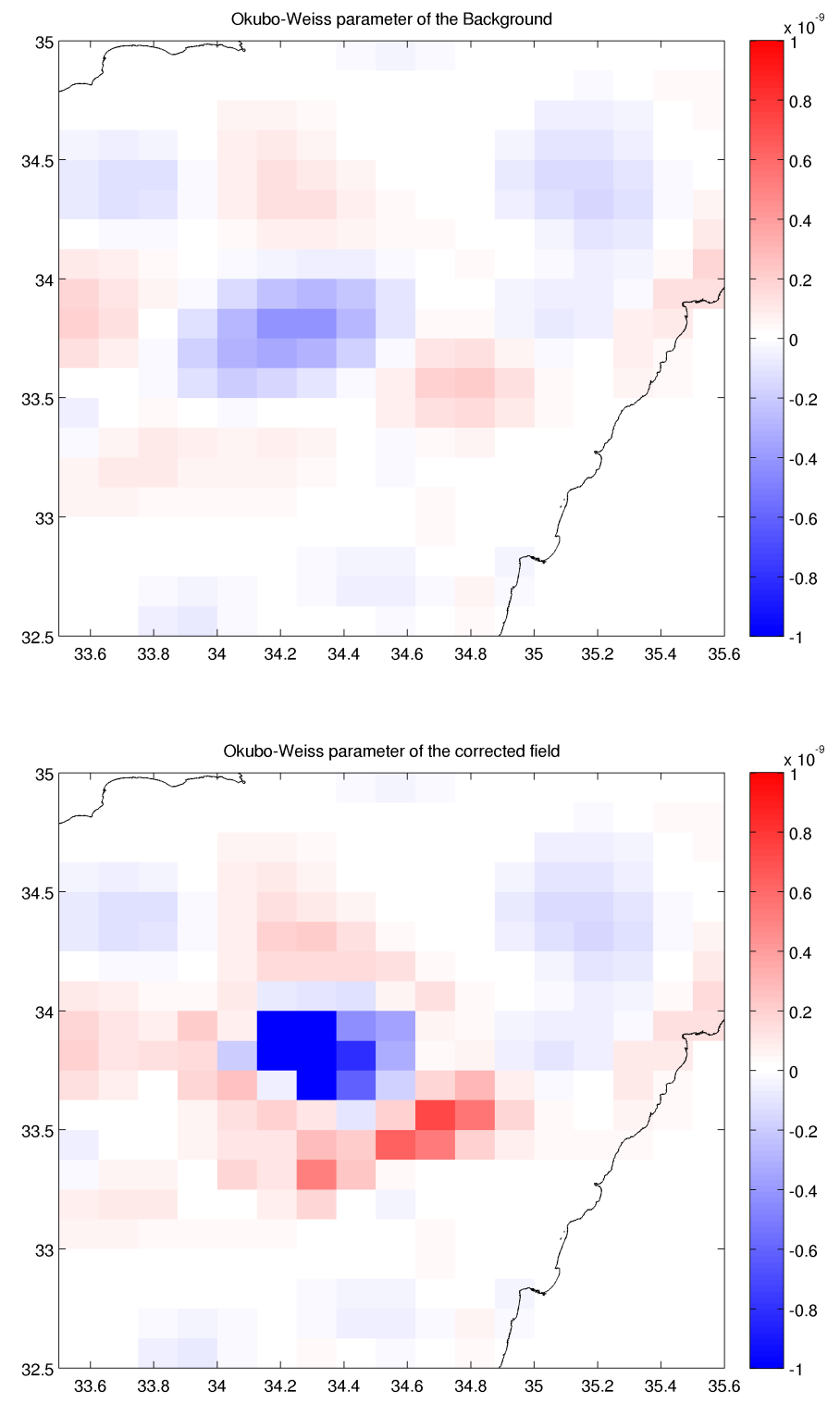

Figure 14: Okubo-Weiss parameter calculated on background field (upper panel) and corrected field (lower panel). The negativity of this parameter characterizes eddies, and the absolute value corresponds to the intensity of the eddy. It can be noticed that eddy is smaller in size and more intense after the correction process. 